\title{
(6) OPEN ACCESS \\ Waterpipe tobacco smoking: what is the evidence that it supports nicotine/tobacco dependence?
}

\author{
Eiman Aboaziza, ${ }^{1}$ Thomas Eissenberg ${ }^{2}$
}

\begin{abstract}
${ }^{1}$ Center for Clinical and
Translational Research and Center for the Study of Tobacco Products, Virginia Commonwealth University, Richmond, Virginia, USA ${ }^{2}$ Department of Psychology, Center for the Study of Tobacco Products, Virginia Commonwealth University, Richmond, Virginia, USA
\end{abstract}

\section{Correspondence to} Dr Thomas Eissenberg, Department of Psychology, Center for the Study of Tobacco Products, Virginia Commonwealth University, 1112 East Clay Street, Suite B-08 (for express mail), PO Box 980205, Richmond, VA 23298, USA; teissenb@vcu.edu

Received 16 September 2014 Accepted 20 November 2014 Published Online First 9 December 2014
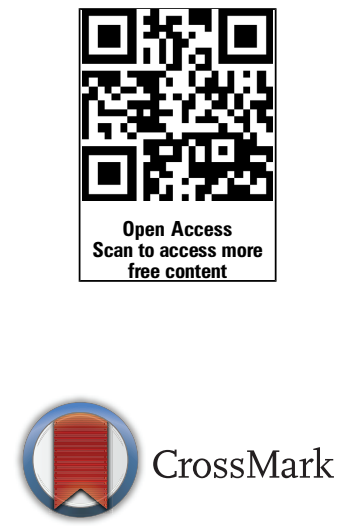

To cite: Aboaziza $\mathrm{E}$ Eissenberg T. Tob Control 2015;24:i44-i53.

\section{ABSTRACT \\ Objective Waterpipe tobacco smoking (WTS) involves passing tobacco smoke through water prior to inhalation, and has spread worldwide. This spread becomes a public health concern if it is associated with tobacco-caused disease and if WTS supports tobaccol nicotine dependence. A growing literature demonstrates that WTS is associated with disability, disease and death. This narrative review examines if WTS supports nicotine/tobacco dependence, and is intended to help guide tobacco control efforts worldwide.}

Data sources PUBMED search using: (("waterpipe" or "narghile" or "arghile" or "shisha" or "goza" or "narkeela" or "hookah" or "hubble bubble")) AND ("dependence" or "addiction").

Study selection Excluded were articles not in English, without original data, and that were not topic-related. Thirty-two articles were included with others identified by inspecting reference lists and other sources.

Data synthesis WTS and the delivery of the dependence-producing drug nicotine were examined, and then the extent to which the articles addressed WTS-induced nicotine/dependence explicitly, as well as implicitly with reference to criteria for dependence outlined by the WHO.

Conclusions WTS supports nicotine/tobacco dependence because it is associated with nicotine delivery, and because some smokers experience withdrawal when they abstain from waterpipe, alter their behaviour in order to access a waterpipe and have difficulty quitting, even when motivated to do so. There is a strong need to support research investigating measurement of WTS-induced tobacco dependence, to inform the public of the risks of WTS, which include dependence, disability, disease and death, and to include WTS in the same public health policies that address tobacco cigarettes.

\section{INTRODUCTION}

Tobacco use causes the death of millions of people each year across the globe, with the most common form-and the most well-studied-being tobacco cigarette smoking. ${ }^{1-3}$ Evidence has accumulated over the past 70 years that documents conclusively that tobacco cigarette smoking causes a variety of lethal conditions, including cardiovascular disease, ${ }^{2}$ cancer (throat, lung, and bladder), ${ }^{2}$ and pulmonary disease (emphysema, chronic obstructive pulmonary disease (COPD)). ${ }^{2}$ In addition to being well-studied, these health risks are well-known and are described clearly to cigarette smokers in public health campaigns that use a variety of media to communicate them (cigarette packs ${ }^{5-8}$; TV advertisement ${ }^{9-12}$; print advertisement ${ }^{9}{ }^{13}$ ). Nonetheless, there is, worldwide, a continuing epidemic of tobacco cigarette smoking and its consequent disability, disease and death. This continuation of a self-destructive behaviour is, at an individual level, attributed to the fact that cigarette smoking supports nicotine/tobacco dependence: a condition in which substance use that initially is controllable becomes compulsive. ${ }^{14-17}$ This change from control to compulsion is a behavioural manifestation of changes in brain physiology that accompany repeated exposure to the drug nicotine. ${ }^{15} 1819$ Much has been written about the features of nicotine/tobacco dependence in cigarette smokers and there is some agreement regarding its indicators, ${ }^{14}{ }^{16}$ though also continued refinement is necessary. ${ }^{20} 21$ Treating nicotine/tobacco dependence in current cigarette smokers is a key component in any public health programme intended to eradicate tobacco-caused morbidity and mortality. ${ }^{22}$

Unfortunately, other, non-cigarette forms of tobacco use are becoming more prevalent worldwide. For example, smoking tobacco using a waterpipe (arghile, hookah, narghile, shisha), is a centuries-old method of tobacco use that has become a new strain in the global tobacco epidemic. ${ }^{23-28}$ As used here, the term 'waterpipe tobacco smoking' (WTS) is intended to include any method of tobacco use in which tobacco smoke is passed through water prior to inhalation by the user. One particularly common method involves using charcoal to heat a sweetened and flavoured tobacco mixture (ma'assel) in a ceramic head that sits atop a conduit that is submerged in a half-full water bowl that has a hose emerging from its top (above the water line; see figure 1). When the user inhales on the mouthpiece at the other end of the hose, negative pressure is formed in the bowl and air is thus drawn over the charcoal. The charcoal-heated air passes though the tobacco (perforated aluminium foil often separates charcoal from tobacco) and a combination of charcoal and tobacco smoke passes through the water and the hose and then into the user's lungs. Previously common in countries located in two world regions, Eastern Mediterranean ${ }^{29-34}$ and Southeast Asia, ${ }^{35-38}$ WTS now can be found in Africa $^{39-41}$ the Americas, ${ }^{24} 353642-44$ Europe ${ }^{45-50}$ and the Western Pacific. ${ }^{51} 52$ As indicated by the WHO, there is little doubt that WTS is a global phenomenon, ${ }^{53}$ and this fact is documented in many reviews, ${ }^{25} 35425455$ as well as elsewhere in this issue. $^{56}$

The worldwide spread of WTS becomes a public health concern if it is associated with tobaccocaused disease and if its use becomes compulsive (ie, supports tobacco/nicotine dependence). There is a growing literature that demonstrates that waterpipe tobacco smoke contains many of the same toxicants as cigarette smoke, ${ }^{50}$ 57-61 that waterpipe 


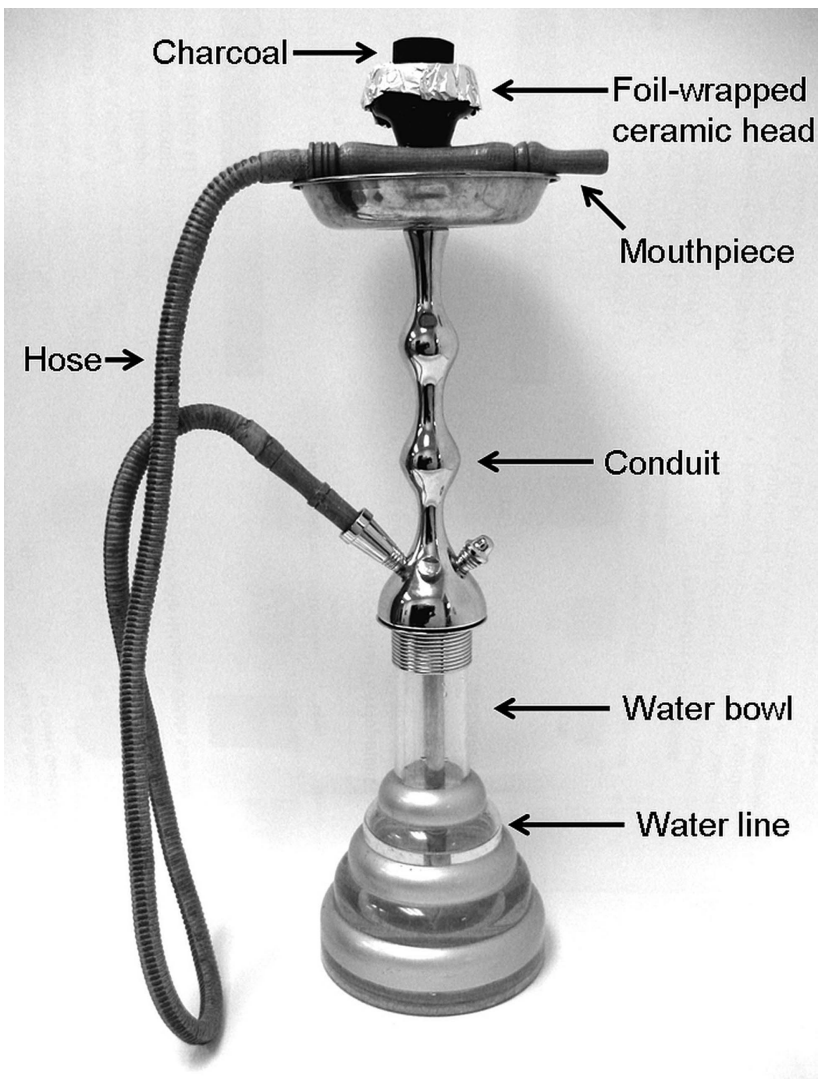

Figure 1 A waterpipe and its component parts.

tobacco smokers are exposed to these toxicants ${ }^{62-66}$ and that WTS is associated with disability, disease and death. ${ }^{67-69}$ This literature has been summarised previously ${ }^{25} \quad 26 \quad 55 \quad 70$ and the most up-to-date review can be found elsewhere in this issue. ${ }^{71}$ The purpose of this review is to examine if, like tobacco cigarette smoking, WTS supports nicotine/tobacco dependence. If it does, the same emphasis given to treating and preventing tobacco cigarette smoking in public health programmes should be extended to WTS. Thus this review is intended to help guide tobacco control efforts worldwide. The review first examines WTS and the delivery of the dependence-producing drug nicotine (the primary dependence-causing agent in cigarette smoke ${ }^{17}{ }^{19}$ ) and then focuses on the extent to which the literature on WTS addresses nicotine/tobacco dependence in waterpipe tobacco smokers.

\section{DOES WTS DELIVER THE DEPENDENCE PRODUCING DRUG NICOTINE?}

Nicotine is a mild psychomotor stimulant that is produced by the tobacco plant. ${ }^{17}$ Therefore, the first step in addressing nicotine delivery in WTS is to determine if nicotine is present in waterpipe tobacco. One study addressing this question ${ }^{72}$ examined the nicotine content of 11 brands of the type of flavoured waterpipe tobacco (ie, ma'assel) in common use today. Results indicated that, on average, the nicotine content was $3.4 \mathrm{mg} / \mathrm{g}$ (range $=1.8-$ $6.3 \mathrm{mg} / \mathrm{g}$ ). This nicotine concentration is less than that reported for 32 brands of tobacco cigarettes (mean $=13.8 \mathrm{mg} / \mathrm{g} ; 9.8-$ $18.2)^{72}$ but, considering that WTS involves placing $10-20 \mathrm{~g}$ of ma'assel into the waterpipe head, the difference in concentration may not be indicative of less nicotine reaching the user. Indeed, understanding nicotine delivery to the user involves an understanding not only of how much tobacco is used, but also the puffing behaviour that generates the smoke that emerges from the waterpipe. While a single puff from a cigarette is usually about $50-100 \mathrm{~mL}^{6373}$ a single puff form a waterpipe is many times that volume (ie, $511 \mathrm{~mL} ;{ }^{66} 833 \mathrm{~mL} ;{ }^{63} 906 \mathrm{~mL}^{74}$ ). In addition, a single WTS episode can last for $30 \mathrm{~min}$ or longer, and can involve $60-169$ puffs, ${ }^{65}{ }^{74}$ so there is ample opportunity for the nicotine in the bowl to be transferred to the user. Analysis of waterpipe smoke generated by a machine programmed to mimic human waterpipe user puff topography demonstrates that the smoke from a WTS episode contains about $1.0 \mathrm{mg}$ nicotine, as compared to $0.73 \mathrm{mg}$ for a standard tobacco cigarette. ${ }^{64}$ Perhaps most important, several studies have demonstrated that plasma nicotine concentrations of waterpipe tobacco smokers are elevated after a WTS episode ${ }^{74-78}$ and that this elevation peaks at concentrations that are greater $\operatorname{than}^{78}$ or similar to those observed in cigarette smokers, ${ }^{62} 6379$ (but see ${ }^{75}$ ). Critically, the nicotine delivered to the user during WTS alters cardiovascular function ${ }^{62} 74$ demonstrating that physiologically active doses of the dependence-producing drug nicotine are delivered to the user during a WTS episode. ${ }^{42}$

\section{DOES THE LITERATURE ON WTS ADDRESS KEY FEATURES OF DEPENDENCE?}

This section presents the method for identifying relevant literature and then presents our narrative review of that literature.

\section{Method for identifying WTS dependence literature}

In order to guide our narrative review of the literature on WTS and tobacco/nicotine dependence, we performed on 7 September 2014 a PUBMED search using the following search string: (“"waterpipe" or "narghile" or "arghile" or "shisha" or "goza" or "narkeela" or "hookah" or "hubble bubble")) AND ("dependence" or "addiction") and it returned 69 hits. We excluded from the list articles not available in English, without original data and that were not directly related to the topic. The remaining set of 32 articles formed the basis of the second portion of this narrative review (these 32 are identified with an asterisk in the reference list of this manuscript), with the addition of several articles not referenced in PUBMED that were identified through inspection of the reference lists of the original 32, as well as other relevant literature.

We first discuss those articles that addressed the issue of nicotine/tobacco dependence in waterpipe tobacco smokers directly, and then discuss those that present data that indirectly are relevant to dependence and WTS, inasmuch as they address behavioural indicators of drug dependence, as outlined by the WHO in its International Classification of Diseases and Health Problems (ICD-10; see table 1). We recognise there are other dependence indicators provided by other sources (eg, the Diagnostic and Statistical Manual of the American Psychiatric Association; APA, 2013), and that whatever set of indicators is used for this purpose will be controversial.

\section{Direct evidence regarding nicotine/tobacco dependence in waterpipe tobacco smokers}

Fourteen published papers addressed nicotine/tobacco dependence and WTS directly. Two of those were relatively early works $^{2680}$ and discussed dependence in the context of survey data that assessed related constructs. One such study examined data from 268 waterpipe tobacco smokers who were recruited in restaurants and cafés in Aleppo Syria and responded to items addressing frequency of WTS, context of WTS, transitions in WTS use patterns and perceptions of feeling 'hooked' and ability to quit WTS. Of those sampled, 24\% were daily, $48.3 \%$ 
weekly and $27.7 \%$ monthly users. Results indicated that more frequent users felt more 'hooked' and engaged more often in WTS alone and at home; they also more often carried a waterpipe with them when one might not be available and preferentially selected venues where one was available. In addition, more frequent users also were more likely to report engaging in WTS more often than when they started and they also reported feeling more 'hooked' on WTS. ${ }^{80}$ More frequent users also had lower self-efficacy regarding cessation of WTS. ${ }^{80}$ These results supported a conclusion, cautiously worded, that WTS may support nicotine/tobacco dependence because it can cause more frequent use than originally intended, drug-seeking behaviour, and decreased feelings of control over the behaviour. In addition, results suggested a potential difference between nicotine/ tobacco dependence in WTS as compared to cigarette smoking: dependence in waterpipe users may be associated with a transition from social to solitary use. Importantly in this work, frequency of use was a proxy measure for dependence itself, while dependence is likely multidimensional. In a related study examining the data from several related surveys ${ }^{26}$ the multidimensional idea of dependence also was discussed. Here, the emphasis was on the intermittent pattern observed in WTS, the variety of specific stimuli that are paired with it, and the social aspects of the behaviour, all of which may act in concert to support associative components of dependence. ${ }^{81}$ Taken together, these issues were thought important enough to support development of waterpipe-specific dependence measures.

The construction and validation of a waterpipe-specific dependence measure has been reported. ${ }^{82}$ The Lebanese Waterpipe Dependence Scale (LWDS-11) consists of 11 Arabic-language items, each scored $0-3$ (see table 2 for the English-language items, response options and scoring). Some items were based on measures used to assess nicotine/tobacco dependence in cigarette smokers and some were included to assess aspects of dependence that may be waterpipe-specific. The scale was validated initially using three separate samples of waterpipe tobacco smokers in Lebanon: a convenience sample of 103 adults $(67 \%$ men; mean age $=29.7$ years; $28.2 \%<2$ waterpipes/week, 44.7\% 3-6 waterpipes/week, $37.5>6$ waterpipes/week), a convenience sample of 15 adults $(66.7 \%$ men; mean age $=27.5$ years; $46.7 \%<2$ waterpipes/week, $26.7 \%$ 3-6 waterpipes/week, 26.7>6 waterpipes/week), and a random sample of 188 adults $(60 \%$ men; mean age $=36.2$ years; $52.7 \%$ $<2$ waterpipes/week, 19.7\% 3-6 waterpipes/week, 27.7>6 waterpipes/week). A principal components analysis revealed four dimensions: 'physiological dependence', 'psychological craving', 'negative reinforcement', and 'positive reinforcement. ${ }^{82}$ Cronbach's $\alpha$ ranged from 0.55 to 0.88 for the subscales, and was 0.83 for the total scale; the test-retest coefficient for the total scale (Spearman's correlation) was $\mathrm{r}=0.92 .{ }^{82}$ Validity was explored by examining correlations with exposure to waterpipe smoke toxicants (ie, carbon monoxide (CO) and nicotine) and waterpipe use frequency and significant relationships were found for some but not all factors. ${ }^{82}$ Based on results with all three samples, the LWDS-11 appeared to have satisfactory psychometric properties and indicated that nicotine/tobacco dependence in waterpipe tobacco smokers can be measured, and, as with cigarette smokers, is multidimensional with aspects related to positive and negative reinforcement. ${ }^{82}$ A social dimension may be unique to WTS, and those users who are not nicotine/tobacco dependent may be occasional smokers who engage in the behaviour to relax or improve morale ${ }^{82} \mathrm{~A}$ subsequent study on a much larger sample of WTS university students in Lebanon (760 individuals completed the LWDS- $11^{83}$ ) confirmed the four dimensions of the scale, though one item (income, see table 2) loaded on 'psychological craving' instead of 'physiological dependence'.

The LWDS-11 has been used to explore nicotine/tobacco dependence in WTS in several ways. First, in a sample of 1066 men and 1134 Lebanese women aged 40 years or older, it has been used to examine gender differences in dependence. ${ }^{84}$ In this sample, women who engaged in WTS were more dependent than men, as indexed by LWDS-11 score $>10$, although there was no difference in smoking frequency and duration between genders. However, in a smaller study of younger waterpipe smokers $(\mathrm{N}=103,77 \%$ below age 35,69 men) no such relationship was revealed, though dependence (as indexed by LWDS-11 score $>10)$ was observed in only 24 cases $(23.3 \%)$. Second, in a case-control study, ${ }^{85}$ waterpipe dependence was associated significantly with chronic bronchitis $(\mathrm{OR}=3.7)$ and as score on the LWDS-11 increased, so did the odds of chronic bronchitis: LWDS-11 scores of $>16$ were associated with an OR of 12.34 (95\% CI 5.65 to 26.96). In a similarly designed case-control study conducted by the same research group in the same regional area, ${ }^{86}$ there was a similar association of increased

Table 1 Criteria for the dependence syndrome according to the Tenth Revision of the International Classification of Diseases and Health Problems (ICD-10) ${ }^{16}$

\section{ICD-10 criteria for dependence syndrome}

1. A strong desire or sense of compulsion to take the substance

2. Impaired capacity to control substance-taking behaviour in terms of its onset, termination or levels of use, as evidenced by the substance being often taken in larger amounts or over a longer period than intended, or by a persistent desire or unsuccessful efforts to reduce or control substance use

3. A physiological withdrawal state when substance use is reduced or ceased, as evidenced by the characteristic withdrawal syndrome for the substance, or by use of the same (or closely related) substance with the intention of relieving or avoiding withdrawal symptoms

4. Evidence of tolerance to the effects of the substance, such that there is a need for significantly increased amounts of the substance to achieve intoxication or the desired effect, or a markedly diminished effect with continued use of the same amount of the substance

5. Preoccupation with substance use, as manifested by important alternative pleasures or interests being given up or reduced because of substance use; or a great deal of time being spent in activities necessary to obtain, take or recover from the effects of the substance

6. Persistent substance use despite clear evidence of harmful consequences as evidenced by continued use when the individual is actually aware, or may be expected to be aware, of the nature and extent of harm

WTS publications addressing each criterion

32669798100101

3298101102

66104

637480100106

2980100

WTS, Waterpipe tobacco smoking. 
Table 2 The Lebanon Waterpipe Dependence Scale (LWDS-11) and its variants

\begin{tabular}{|c|c|c|c|c|}
\hline Item & Response options and scoring & LWDS- $11^{83}$ factor & LWDS-10J ${ }^{90}$ factor & LWDS-10 $0^{91}$ factor \\
\hline $\begin{array}{l}\text { 1. Number of times you could stop } \\
\text { waterpipe for }>7 \text { days? }\end{array}$ & $\begin{array}{l}\text { None (3) } \\
\text { Once (2) } \\
\text { Several } \\
\text { times (1) } \\
\text { It always happens (0) }\end{array}$ & $\begin{array}{l}\text { Physiological nicotine } \\
\text { dependence }\end{array}$ & Physical dependence & Physiological dependence \\
\hline $\begin{array}{l}\text { 2. Percent of income you would spend on } \\
\text { waterpipe smoking? }\end{array}$ & $\begin{array}{l}1 \% \text { or less of your monthly income }(0) \\
2-10 \% \text { of your monthly income }(1) \\
11-50 \% \text { of your monthly income }(2) \\
\text { More than } 50 \%(3)\end{array}$ & $\begin{array}{l}\text { Physiological nicotine } \\
\text { dependence* }\end{array}$ & Physical dependence & Physiological dependence \\
\hline $\begin{array}{l}\text { 3. Number of days you could spend } \\
\text { without waterpipe? }\end{array}$ & $\begin{array}{l}\text { One day or less (3) } \\
2-3 \text { days (2) } \\
4-7 \text { days ( } 1 \text { ) } \\
\text { More than } 7 \text { days (0) }\end{array}$ & $\begin{array}{l}\text { Physiological nicotine } \\
\text { dependence }\end{array}$ & Physical dependence & Physiological dependence \\
\hline $\begin{array}{l}\text { 4. Number of water pipes you usually } \\
\text { smoke per week? }\end{array}$ & $\begin{array}{l}<1 \text { waterpipe/week (0) } \\
1-2 \text { waterpipes/week (1) } \\
3-6 \text { waterpipes/week (2) } \\
7 \text { or more waterpipes/week (3) }\end{array}$ & $\begin{array}{l}\text { Physiological nicotine } \\
\text { dependence }\end{array}$ & Physical dependence & Physiological dependence \\
\hline $\begin{array}{l}\text { 5. Do you smoke waterpipe to relax your } \\
\text { nerves? }\end{array}$ & $\begin{array}{l}\text { Yes, absolutely ( } 3 \text { ) } \\
\text { Yes, probably ( } 2 \text { ) } \\
\text { Yes, maybe (1) } \\
\text { No (0) }\end{array}$ & Negative reinforcement & Relaxation/pleasure & Positive/negative reinforcement \\
\hline $\begin{array}{l}\text { 6. Do you smoke waterpipe to improve } \\
\text { your morale? }\end{array}$ & $\begin{array}{l}\text { Yes, absolutely ( } 3 \text { ) } \\
\text { Yes, probably ( } 2 \text { ) } \\
\text { Yes, maybe (1) } \\
\text { No (0) }\end{array}$ & Negative reinforcement & Psychosocial & Positive/negative reinforcement \\
\hline $\begin{array}{l}\text { 7. Do you smoke waterpipe when you are } \\
\text { seriously ill? }\end{array}$ & $\begin{array}{l}\text { Yes, absolutely ( } 3 \text { ) } \\
\text { Yes, probably ( } 2 \text { ) } \\
\text { Yes, maybe (1) } \\
\text { No (0) }\end{array}$ & Psychological craving & Physical dependence & Physiological dependence \\
\hline 8. Do you smoke waterpipe alone? & $\begin{array}{l}\text { Yes, always ( } 3 \text { ) } \\
\text { Yes, most of the times ( } 2 \text { ) } \\
\text { Yes, sometimes (1) } \\
\text { No, never }(0)\end{array}$ & Psychological craving & Physical dependence & Physiological dependence \\
\hline $\begin{array}{l}\text { 9. Are you ready not to eat in exchange } \\
\text { for a waterpipe? }\end{array}$ & $\begin{array}{l}\text { Yes, absolutely ( } 3 \text { ) } \\
\text { Yes, probably ( } 2 \text { ) } \\
\text { Yes, maybe (1) } \\
\text { No (0) }\end{array}$ & Psychological craving & $t$ & $t$ \\
\hline $\begin{array}{l}\text { 10. Do you smoke waterpipe for } \\
\text { pleasure? }\end{array}$ & $\begin{array}{l}\text { Yes, absolutely ( } 3 \text { ) } \\
\text { Yes, probably ( } 2 \text { ) } \\
\text { Yes, maybe (1) } \\
\text { No (0) }\end{array}$ & Positive reinforcement & Relaxation/pleasure & Positive/negative reinforcement \\
\hline $\begin{array}{l}\text { 11. Do you smoke to please others } \\
\text { (conviviality)? }\end{array}$ & $\begin{array}{l}\text { Yes, absolutely (3) } \\
\text { Yes, probably (2) } \\
\text { Yes, maybe (1) } \\
\text { No (0) }\end{array}$ & Positive reinforcement & Psychosocial & Positive/negative reinforcement \\
\hline
\end{tabular}

* Income item was loaded on psychological craving in a study of university students. ${ }^{81}$ tRemoved from LWDS-10J ${ }^{87}$ and LWDS-10. ${ }^{88}$

LWDS-11 scale score and COPD: LWDS-11 scores of $<10$ were associated with an OR of 0 , for scores of 10-16 the OR was 5.56 , and for scores $>16$ the OR was 12.24 (all relative to never-smokers). This effect of dependence on bronchitis and COPD may be due to greater toxicant exposure in more dependent waterpipe tobacco smokers. In a study of Jordanian waterpipe tobacco smokers who either scored low $(<7)$ or high $(>13)$ on the LWDS-11 and then smoked a waterpipe in a laboratory setting, higher LWDS-11 scores were associated with more puffs, longer puffs, shorter interpuff intervals, lower flow rate (puff velocity), and greater exposure to $\mathrm{CO}$ during the smoking session. ${ }^{87}$ As the authors noted: "The observation that smokers with higher LWDS-11 scores are exposed to more CO suggests that these individuals may inhale more smoke and thus be at greater risk for waterpipe-induced cardiovascular and pulmonary disease as well as cancer..." (ref. 87, p. 1785; see also ref. 88 for a potential mechanism relating WTS to COPD).
Thus, the LWDS-11 is a validated instrument used for measuring nicotine/tobacco dependence in waterpipe tobacco smokers and may have utility in identifying individuals who are at risk for developing tobacco-caused disease.

The LWDS-11 has been modified based on empirical observation outside of Lebanon. In one such study, the scale was included in a survey of a representative sample of 5853 students (recruited over 3 years) from four Jordanian universities who responded to an Arabic-language instrument. ${ }^{89}$ Of the original sample, 3278 students reported 'ever waterpipe use' and therefore responded to the LWDS-11 items. Their data were divided randomly with the first half undergoing exploratory and the second half confirmatory factor analysis; convergent validity was also examined. Here, a three factor solution using 10 of the original LWDS-11 items was obtained (see table 2; the omitted item was: 'Are you ready not to eat in exchange for a waterpipe?'). Confirmatory analysis revealed a good fit and significant 
associations between dependence scores and dependence risks such as average number of tobacco heads/session, age of waterpipe initiation and number of waterpipes owned were observed. The resulting scale, the LWDS-10J (J for 'Jordan') with its three factors corresponding to 'physical dependence', 'relaxation/ pleasure', and 'psychosocial aspects', may be particularly valuable for studies of Arabic-speaking university students.

In another such study, the LWDS-11 was administered to 180 waterpipe tobacco smokers (mean age $=29.5, \mathrm{SD}=9.4 ; 52.2 \%$ history of daily WTS; $21 \%$ smoked their last waterpipe alone) who were recruited from waterpipe cafés in central London, England. ${ }^{90}$ As with the LWDS-10J, psychometric analysis led to the elimination of the item 'Are you ready not to eat in exchange for a waterpipe?'. Unlike the LWDS-11 and the LWDS-10J, subsequent analysis led to a two factor solution in which items loaded on domains of 'physiological dependence' and 'positive and negative reinforcement'. Again, psychometric properties of the scale, now relabelled the Lebanon Waterpipe Tobacco Dependence Scale (LWTDS) were generally strong and, $47 \%$ of the sample scored greater than 10 on it, indicating dependence. Indeed, there was a significant association between weekly waterpipe smoking frequency and scale score (see figure 2), again suggestive of the face validity of the measure. This study was the first to apply the LWDS-11 to non-Arabic-speaking sample, and it highlights the need for further refinement of measures of dependence in waterpipe tobacco smokers that are generalisable and usable across cultures. ${ }^{90}$ As noted elsewhere, ${ }^{91}$ there is a growing need for waterpipe-specific measures of dependence that are validated for use in other populations where WTS is common. ${ }^{92}$

One article explicitly discussed nicotine/tobacco dependence and WTS without reference to the LWDS-11. ${ }^{32}$ Here, two instruments commonly used to assess dependence in tobacco cigarette smokers, the Fagerström Test for Nicotine Dependence $\left(\right.$ FTND $\left.;{ }^{93}\right)$ and the negative affect, addiction and stimulation subscales of the Horn-Waingrow Reasons for Smoking (RFS $;^{94}$ ) scale were modified by substituting the word 'shisha' for 'cigarette' as necessary. ${ }^{32}$ One hundred and fifty-four Egyptian men who were exclusive waterpipe smokers responded to the modified instruments that were administered via interview. The mean age of the sample was 47 years $(S D=14$; range $=19-88)$ and $95 \%$ of those responding were daily waterpipe users with an average daily consumption of $4(\mathrm{SD}=8)$ heads of tobacco.

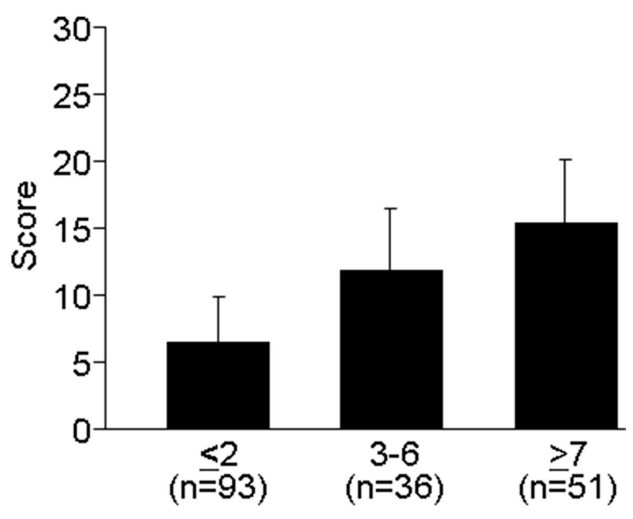

Number of waterpipe uses/week

Figure 2 Mean scores $( \pm$ SEM) on the Lebanon Waterpipe Tobacco Dependence Scale (LWTDS; see ref. 90) by self-reported use frequency. There was a statistically significant difference between the groups. Figure made using data from Kassim et al. ${ }^{90}$
Results from the modified FTND indicated that respondents with more frequent waterpipe use patterns were more likely to report using a waterpipe to smoke tobacco within the first hour after waking, to smoke a waterpipe even when ill, and to tolerate less than a day without smoking. ${ }^{32}$ Results from the modified RFS subscales indicated that the addiction subscale scores were associated significantly with all FTND items, while '[s]moking to relieve negative affect was significantly and positively associated with increased frequency and intensity of waterpipe smoking, shorter duration before symptoms of craving and smoking when ill. Smoking for stimulation was significantly and positively associated with intensity (not frequency) of smoking, younger age of onset, smoking when ill and shorter duration before symptoms of craving" (ref. 32, p. 134).

In sum, nicotine/tobacco dependence can be measured in waterpipe tobacco smokers using one of the several variants of the LWDS-11. The instrument has acceptable psychometric properties, even when used in different contexts than that in which it was validated originally. There is a clear need to continue refining the LWDS and its variants, particularly with regard to determining its predictive validity against cessationrelated outcomes (ie, quitting and relapse). Nonetheless, our analysis revealed that scores on the LWDS are associated with frequency of use as well as disease states that are likely attributable to WTS. There is general agreement among those studies in which the LWDS has been included that WTS produces nicotine/tobacco dependence, that this dependence has both physiological and psychological/social components, and that further work is needed to develop a more robust instrument that assesses in greater detail the multidimensional aspects of nicotine/dependence across cultures.

\section{Indirect evidence regarding nicotine/tobacco dependence in waterpipe tobacco smokers}

In addition to work assessing WTS-associated nicotine/tobacco dependence directly, a group of published studies provide indirect evidence that waterpipe-tobacco smokers experience a variety of indicators of nicotine/tobacco dependence. One potentially useful method for discussing these studies is to select a set of criteria for dependence and determine to what extent the study results address each criterion. The WHO's ICD-10 provides criteria for dependence that might be used in research (see table 1) and below each of these criteria is discussed in terms of these studies that indirectly touch on nicotine/dependence in WTS.

As table 1 shows, one dependence criterion addresses 'A strong desire or sense of compulsion to take the substance'. There are a variety of strategies that might be used to establish that this 'strong desire' exists in an individual who may be drug dependent, including behavioural indices that have been applied to the study of nicotine/tobacco dependence in cigarette smokers. ${ }^{95} 96$ We are aware of no studies that have applied these or any related behavioural task to WTS. However, several studies address this criterion using subjective measures, often items assessing 'craving' or 'urge'. For example, in a laboratory study of 61 Syrian waterpipe tobacco smokers who also smoked cigarettes (mean age \pm SD 22.0 2.6 year; mean cigarettes/day $22.4 \pm 10.1$; mean waterpipes/week 5.2 \pm 5.6 ), a $12 \mathrm{~h}$ period of tobacco abstinence preceded assessment of 'urge to smoke' and other measures, followed by a session in which smoking occurred (on 1 day, a cigarette; on another day, a waterpipe) and 'urge to smoke' and other measures were reassessed. ${ }^{97}$ Self-reported 'urge to smoke' was high before smoking (approximately $65-80$ on a 100 point scale) and decreased significantly 
after smoking the waterpipe or the cigarette. Since participants in this study were occasional cigarette smokers, the specificity of these results to WTS is uncertain. However, near-identical results were observed in a similarly designed study of 61 Syrian participants who were exclusive waterpipe smokers (mean age $=30.9, \mathrm{SD}=9.5$; mean numbe of weekly waterpipe smoking episodes $=7.8, \mathrm{SD}=5.7$; mean duration of WTS $=8.5$ years, $\mathrm{SD}=6.1) .{ }^{67}$ In this study, participants abstained from tobacco use for $24 \mathrm{~h}$ before smoking a waterpipe in a laboratory. Mean presmoking 'urge to smoke' scores were $39.5(\mathrm{SD}=33.2)$ and decreased significantly to $22(\mathrm{SD}=30.2)$, while mean presmoking 'craving a waterpipe/nicotine' scores were $36.7(\mathrm{SD}=35.8)$ and decreased significantly to $18 \quad(\mathrm{SD}=25.8)$. Self-reported craving also was assessed in a previously mentioned study, ${ }^{32}$ in that participants were asked to report how many hours they could go without WTS before they felt craving: results indicated that individuals with more frequent daily WTS use patterns were significantly more likely to experience craving sooner. Craving has also been reported in a survey of waterpipe tobacco smokers in the UK, ${ }^{98}$ qualitative studies of Syrian ${ }^{99}$ or British waterpipe smokers, ${ }^{100}$ as well as in a laboratory study of waterpipe tobacco smokers in the USA. ${ }^{63}$ Unfortunately, in none of these studies was there a validated dependence measure that was administered to participants (eg, the LWDS-11 or its variants) so there is no way of knowing to what extent abstinence-induced urge/craving or its subsequent suppression due to smoking was correlated with nicotine/dependence level as assessed by that instrument.

Another ICD-10 dependence criterion involves impaired capacity to control substance use behaviour (table 1), and can be indexed, in part, by unsuccessful attempts to reduce use of the substance. Several studies provide evidence that WTS is associated with these unsuccessful attempts. For example, in one study cited previously, ${ }^{32} 63 \%$ of participants (95/151; all current waterpipe tobacco smokers) reported previous attempts that, clearly, were unsuccessful. Similarly, in the UK university survey, ${ }^{98} 2$ of the 21 regular waterpipe tobacco smokers reported unsuccessful quit attempts. Quitting waterpipe smoking was the primary focus of two separate studies using distinct methodology. One was a survey study, involving a random sample of 268 waterpipe tobacco smokers in Aleppo, Syria $(40 \%$ female; mean age $=30$ years; range $=18-68 ; 20.3 \%$ smoked waterpipe daily). ${ }^{101}$ Seventy-six of these individuals reported an interest in quitting and 45 had made a previous quit attempt (clearly unsuccessful) in the past year. ${ }^{101}$ The second paper reports the results of a pilot study of a behavioural intervention designed to help waterpipe tobacco smokers quit. ${ }^{102}$ Fifty exclusive waterpipe tobacco smokers with a pastyear history of WTS $\geq 3$ times/week ( $70 \%$ with at least one pastyear quit attempt) were randomised to either a brief $(n=23)$ or intensive $(n=27)$ behavioural intervention, and intervention efficacy was evaluated 3 months after it ended using a combination of self-report and objective verification of tobacco abstinence (ie, expired air $\mathrm{CO}$ concentration $<10 \mathrm{ppm}$ ). Although readiness to quit was endorsed by $84 \%$ of participants, and $80 \%$ reported they were very confident or moderately confident in their ability to quit, continuous, objectively verified abstinence was observed in $9 / 50$ participants (ie, $18 \%$ ) and objectively verified prolonged abstinence ( 7 day grace period from quit date) observed in 19/50 participants (38\%); there was no statistically significant difference between interventions. ${ }^{102}$ To the extent that these results are generalisable, they are the strongest data available that demonstrate that the majority of motivated waterpipe tobacco smokers who want to quit are unable to do so, even when offered the assistance of a behavioural intervention. Taken together, the existing literature makes clear that there are waterpipe tobacco smokers who want to quit, have tried to quit and who have been unsuccessful at quitting. These individuals may well be experiencing one indicator of nicotine/tobacco dependence associated with WTS: unsuccessful efforts to reduce or control substance use.

Another ICD-10 indicator of dependence refers to the occurrence of a withdrawal syndrome, ${ }^{16}$ an aversive constellation of signs/symptoms that occurs spontaneously following abrupt termination of the dependence-producing substance. ${ }^{81}$ Evidence for this withdrawal syndrome might come from laboratory studies in which exclusive waterpipe smokers are required to abstain from all tobacco use prior to completing standardised questionnaires used to assess nicotine/tobacco abstinence. One such study has been cited previously and provides some evidence that abstinence produces elevated levels of some withdrawal symptoms. ${ }^{67}$ Unfortunately, other laboratory studies using similar methodology involved individuals who use other tobacco products in addition to waterpipe ${ }^{64} 97$ or occasional waterpipe users who either demonstrably were not dependent based on the LWDS- $11^{103}$ or who may not have been dependent based on an infrequent use history (ie, 2-5 episodes monthly ${ }^{74}$ ). However, one recent study compares the effects of a $12 \mathrm{~h}$ abstinence period in frequent $(\geq 20$ monthly episodes, $n=17$ ) and occasional (2-5 episodes monthly; $\mathrm{n}=63$ ) users. ${ }^{104}$ While the relatively small sample size in the frequent user group may have influenced study sensitivity adversely, elevated scores on several withdrawal-related measures were observed in the frequent users relative to the occasional users (eg, both factors of the modified Questionnaire of Smoking Urges). Interpreting these results is made challenging by the absence of an assessment of participant dependence using a validated scale (eg, the LWDS-11). Nonetheless, the results are consistent with the notion that, as use frequency increases, abstinence-induced withdrawal symptoms are more likely.

ICD-10 also indicates that tolerance, or the decreasing effects of a drug with repeated administration, is an indicator of dependence. Acute tolerance to the cardiovascular effects of nicotine has long been known to occur ${ }^{105}$ and this effect has also been demonstrated in waterpipe smokers. ${ }^{63} 74$ That is, during waterpipe use, nicotine levels increase steadily over the first $25 \mathrm{~min}$ of a use episode, but heart rate increases are observed during the first 5-15 min only, and after that stabilise at a level that is higher than before smoking, but without continued increase. ${ }^{6374}$ However, this acute effect is likely less relevant to dependence assessment than is an increased waterpipe use frequency over time, which has been reported in qualitative research $^{99}$ as well as survey studies. For example, in a previously cited survey of 268 Syrian waterpipe smokers, 114 (42.5\%) reported that they smoke waterpipe more frequently when surveyed as compared to when they started. ${ }^{80}$ Prospective study of waterpipe use may be the most effective method to determine the extent to which tolerance and thus increased WTS over time occurs reliably. This effect may well occur, and one prospective study that investigated it in Jordanian youth (age 13-16 years) suggests that tolerance may manifest itself not as increased waterpipe use but rather initiation and increasing use of tobacco cigarettes. ${ }^{106}$ If this form of 'cross-tolerance' from waterpipe toward cigarettes is reliable and generalises to other populations, it further supports the idea that WTS is a grave and immediate public health threat.

The ICD-10 criteria for substance dependence also include preoccupation with substance use, as indexed by reduction of 
other activity or spending a great deal of time in seeking, preparing and/or consuming the substance (table 1). This concept has been discussed in qualitative studies of waterpipe users. ${ }^{29}{ }^{100}$ In one, a participant notes 'Sometimes it bothers me -if I want it [waterpipe] I don't just forget about it-I'll do anything just to have it...I don't know why' (ref. 100, p. 1367). In another, a participant discusses the use of portable waterpipes to ensure that users have the ability to engage in WTS wherever they go. ${ }^{29}$ Indeed, in a survey of Syrian waterpipe smokers, daily and weekly smokers were much more likely to note that they carried a waterpipe with them if needed, and that the availability of waterpipe was a factor in their choice of restaurant/ café. ${ }^{80}$ More work is needed to address the extent to which waterpipe tobacco smokers meet this ICD 10 criterion.

One of the most compelling indicators of dependence may be continued use despite known adverse health effects (table 1). Unfortunately, this compelling indicator is also the most difficult to address empirically today, primarily because the health effects of WTS have been understudied for decades and are only beginning to be revealed (Zaatari et al, under review). Too often, interviews and surveys reveal that WTS is considered to be a low risk activity ${ }^{107-109}$ or, when health risks are acknowledged, they may be downplayed because they are reported inconsistently ${ }^{110}$ and/or perceived to be less than those associated with cigarette smoking. ${ }^{111-113}$ This perception likely is strengthened by labelling of waterpipe tobacco that demonstrably is misleading. ${ }^{114}$ In this context of poorly communicated health effects and misleading labelling, the well-documented global spread of WTS is unsurprising and the likelihood of documenting continued use despite known adverse health effects is unlikely.

\section{SYNTHESIS AND IMPLICATIONS}

The evidence reviewed here makes very clear that WTS supports nicotine/tobacco dependence, at least in some users. To summarise: WTS is associated with the delivery of physiologically active doses of the dependence producing drug nicotine, some waterpipe tobacco smokers engage in nicotine self-administration via waterpipe on a daily basis (sometimes multiple times/day ${ }^{32}$ ), and the literature documents that waterpipe tobacco smokers experience withdrawal, alter their behaviour in order to access a waterpipe and have difficulty quitting, even when motivated to do so. Without doubt, there is a need for instruments that measure WTS-induced nicotine/tobacco smoking more reliably and with greater sensitivity to the multidimensional nature of dependence, greater attention to waterpipe-specific dependence characteristics, and with greater validity and reliability across cultures. ${ }^{32} 92$ Such a measure or measures would be helpful in characterising the extent of the spread of WTS-induced dependence worldwide. However, the lack of such a measure and the data it would generate, whatever they might be, should not be used to justify inaction in the face of a growing epidemic. Rather, it should spur those with a strong interest in public health to take several actions: (1) support research investigating methods to measure WTS-induced tobacco dependence, (2) inform the public of the risks of WTS, which include dependence, (3) include WTS in the same public health policies that address tobacco cigarettes.

While the data presented here indicate that WTS can support nicotine/tobacco dependence, they do not provide much information with regard to the population-wide prevalence of WTS-induced dependence, nor do they allow a definitive determination of the factors that lead some users to become dependent while others do not. This information is sorely needed, and its lack may underlie recent commentary suggesting that, in populations in which WTS is becoming more prevalent today, the likelihood of dependence is unclear. ${ }^{115}$ This lack of clarity must be addressed empirically, and there is an urgent need for a waterpipe-specific dependence measure that takes into account features of this method of tobacco use that make it different from other forms, including its time-consuming preparation and consumption, intermittent use patterns and variety of unique sensory cues. ${ }^{91}$ Such a measure will benefit from research regarding cigarette smoking and smokeless tobacco use, but also likely will require a broad, conceptual mapping approach that takes advantage of current theory in drug dependence as well as expert consensus and makes extensive use of the literature reviewed here to guide item selection. Detailed formative work with waterpipe tobacco smokers would also be valuable, in order to include relevant domains and enhance the representativeness and stability of the domains that are captured. Since waterpipe use is global, a cross-cultural approach to instrument development likely is needed, so that the prevalence of WTS-induced dependence can be studied worldwide. ${ }^{116} 117$ When this measure is available, it can be used to strengthen all areas of study, including human laboratory, clinical trial and epidemiological methods that have already been applied to understanding WTS. In short, stakeholders interested in addressing empirically the growing epidemic of WTS should provide the support necessary for the development of a theoretically based, psychometrically sound instrument for measuring WTS-induced nicotine/tobacco dependence wherever waterpipe use occurs.

Support also is needed to inform the public, especially at-risk populations like young adults, of the health threats associated with WTS. In many countries, extensive public health campaigns make clear that tobacco cigarette smoking causes dependence, disability, disease and death. The omission of WTS from these campaigns unintentionally may reinforce perceptions among waterpipe users and non-users that WTS does not carry the same risks. In fact, not only are there long-term disease risks from WTS ${ }^{688586}$ but there are immediate, short-term risks as well: few users and non-users are likely aware that WTS can cause acute CO intoxication. ${ }^{67}{ }^{118-121}$ An illusion of safety may arise when misperceptions about short-term and long-term health risks are coupled with lack of clarity regarding dependence. Knowledge can help shatter the illusion. Again, stakeholders interested in addressing the global spread of WTS must act to ensure that the public is informed that this form of tobacco use, like tobacco cigarettes, can cause dependence, disability, disease and death.

Policy is another critical area for addressing the WTS epidemic. Policy interventions such as increased taxes on cigarettes, bans on cigarette advertising and promotions (eg, free packs of cigarettes) and regulation of cigarette labelling have contributed to dramatic reductions in cigarette smoking in various countries. ${ }^{122-126}$ Since these policies are effective, they were incorporated into the Framework Convention on Tobacco Control (FCTC), the WHO's first international treaty. ${ }^{127-129}$ The FCTC outlines evidence-based tobacco control policies that, if implemented properly, have the potential to reduce tobacco use. Importantly, while the FCTC is intended to address tobacco generally, it does not address waterpipe specifically and many of its provisions are being applied to cigarettes only. This uneven application of FCTC provisions is particularly apparent where product labelling is concerned:

Article 11 of the FCTC, which specifically addresses packaging and labelling of tobacco products, prescribes a rotating series of health warnings that should cover at least $50 \%$ (or must cover at 
least $30 \%$ ) on average of the front and back of the package. ... A key aspect of Article 11 is a ban on misleading descriptors; the article text states that 'tobacco product packaging and labelling do not promote a tobacco product by any means that are false, misleading, deceptive or likely to create an erroneous impression about its characteristics, health effects, hazards or emissions'. (ref. 130, p. 235)

In fact, waterpipe tobacco products from many countries do not comply with these restrictions: in a sample of 79 WTS tobacco products from nine different countries, the textual labels on packages covered, on average, 3.5\% of total surface area. ${ }^{130}$ Perhaps more important, $77 \%$ of waterpipe tobacco was labelled as ' $0 \%$ Tar' despite the fact that waterpipe tobacco smoke contains substantial tar, $^{65}$ and $64 \%$ were labelled as either ' $0.05 \%$ nicotine' or ' $0.5 \%$ nicotine' despite the fact that these descriptors are not related to actual nicotine delivery. ${ }^{114}$ Thus, current global tobacco control policy does not address WTS specifically, is not applied to WTS, and therefore likely fails to influence WTS. The same situation exists for US tobacco control policy. In the USA, the most important indicator of this policy failure is the Family Smoking Prevention and Tobacco Control Act (FSPTCA). In the FSPTCA, flavoured cigarettes are banned but flavoured waterpipe tobacco is not. Moreover, state and local ordinances that ban cigarette smoking indoors often contain loopholes that allow use of waterpipe indoors. In addition, there is very little effort to develop effective treatments for waterpipe tobacco smokers. ${ }^{131}$ This failure to address WTS explicitly at the global, federal, state and local level and the paucity of treatment options, all may contribute to the spread of WTS because it allows the continued sale of sweetened and flavoured tobacco that attracts new users, often exempts WTS from indoor smoking bans, permits misleading labelling, and fails to help current users quit, ultimately leads users to believe that because WTS is less regulated than cigarettes, it is also less dependence-producing and less lethal.

\section{CONCLUSION}

This review of the literature on WTS and dependence began with a simple statement: 'The worldwide spread of WTS becomes a public health concern if it is associated with tobaccocaused disease and if its use becomes compulsive (ie, supports tobacco/nicotine dependence)'. Evidence presented here and elsewhere in this volume makes clear that both conditions have been met. Better instruments are needed to understand the prevalence of WTS-induced dependence. While those instruments are being developed, public health efforts can be focused on informing users and non-users about the risk of dependence and other health effects associated with WTS, and including WTS in public health policy, including treatment interventions, aimed at reducing the global burden of tobacco-caused morbidity and mortality.

\section{What this paper adds}

This narrative review provides a synthesis of existing research examining the extent to which waterpipe tobacco smoking (WTS) supports nicotine/tobacco dependence.

Contributors The literature search was performed by TE. EA wrote the first draft of the manuscript and prepared the tables. TE prepared the figures. EA and TE participated in the editing of subsequent drafts. TE is the guarantor.
Funding This work was supported by the National Institute on Drug Abuse of the National Institutes of Health under Award Number P50DA036 105, the Center for Tobacco Products of the US Food and Drug Administration (TE), and the Ministry of Higher Education and Scientific Research, Libya (EA). The content is solely the responsibility of the authors and does not necessarily represent the official views of the National Institutes of Health, the Food and Drug Administration or the Libyan Ministry of Higher Education.

\section{Competing interests None.}

Provenance and peer review Commissioned; externally peer reviewed.

Open Access This is an Open Access article distributed in accordance with the Creative Commons Attribution Non Commercial (CC BY-NC 4.0) license, which permits others to distribute, remix, adapt, build upon this work non-commercially, and license their derivative works on different terms, provided the original work is properly cited and the use is non-commercial. See: http://creativecommons.org/ licenses/by-nc/4.0/

\section{REFERENCES}

1 World Health Organization. World Health Organization Report on the Global Tobacco Epidemic, 2011: Warning about the dangers of tobacco. Geneva, 2011.

2 US Department of Health and Human Services. The Health Consequences of Smoking: 50 Years of Progress. A Report of the Surgeon General. Atlanta, GA: US Department of Health and Human Services, Centers for Disease Control and Prevention, National Center for Chronic Disease Prevention and Health Promotion, Office on Smoking and Health, 2014

3 Centers for Disease Control and Prevention. Smoking-attributable mortality, years of potential life lost, and productivity losses-United States, 2000-2004. Morb Mortal Wkly Rep 2008:57:1226-8.

4 Warren GW, Alberg AJ, Kraft AS, et al. The 2014 Surgeon General's report: "The Health Consequences of Smoking-50 Years of Progress": a paradigm shift in cancer care. Cancer 2014;120:1914-16.

5 Mays D, Niaura RS, Evans WD, et al. Cigarette packaging and health warnings: the impact of plain packaging and message framing on young smokers. Tob Control 2015;24:e87-92.

6 Brose $L S$, Chong CB, Aspinall E, et al. Effects of standardised cigarette packaging on craving, motivation to stop and perceptions of cigarettes and packs. Psychol Health 2014;29:849-60.

7 Guillaumier A, Bonevski B, Paul C, et al. Socioeconomically disadvantaged smokers' ratings of plain and branded cigarette packaging: an experimental study. BMJ Open 2014;4:e004078.

8 Fathelrahman Al, Li L, Borland R, et al. Stronger pack warnings predict quitting more than weaker ones: finding from the ITC Malaysia and Thailand surveys. Tob Induc Dis 2013;11:20.

9 Centers for Disease Control and Prevention. Antismoking messages and intention to quit-17 countries, 2008-2011. MMWR Morb Mortal Wkly Rep 2013:62:417-22.

10 McVey D, Stapleton J. Can anti-smoking television advertising affect smoking behaviour? Controlled trial of the Health Education Authority for England's anti-smoking TV campaign. Tob Control 2000;9:273-82.

11 Li L, Borland $\mathrm{R}$, Yong $\mathrm{HH}$, et al. Reported exposures to anti-smoking messages and their impact on Chinese smoker's subsequent quit attempts. Int J Behav Med 2014:21:667-6.

12 Brennan E, Durkin SJ, Cotter T, et al. Mass media campaigns designed to support new pictorial health warnings on cigarette packets: evidence of a complementary relationship. Tob Control 2011;20:412-18.

13 Bayer R, Gostin LO, Javitt GH, et al. Tobacco advertising in the United States: a proposal for a constitutionally acceptable form of regulation. JAMA 2002;287:2990-5.

14 American Psychiatric Association. Diagnostic and statistical manual of mental disorders. 5th edn. Arlington, VA: American Psychiatric Association, 2013:571-4.

15 Centers for Disease Control and Prevention (US); National Center for Chronic Disease Prevention and Health Promotion (US); Office on Smoking and Health (US). How Tobacco Smoke Causes Disease: The Biology and Behavioral Basis for Smoking-Attributable Disease: A Report of the Surgeon General. Atlanta, GA: Centers for Disease Control and Prevention (US), 2010.

16 World Health Organization. The ICD-10 classification of mental and behavioural disorders: clinical descriptions and diagnostic guidelines. Geneva: World Health Organization, 1992.

17 US Department of Health and Human Services. The Health Consequences of Smoking: Nicotine Addiction. A Report of the Surgeon General. Rockville, Maryland: US Department of Health and Human Services, Centers for Disease Control and Prevention, National Center for Chronic Disease Prevention and Health Promotion, Office on Smoking and Health, 1988.

18 Mansvelder HD, De Rover M, McGehee DS, et al. Cholinergic modulation of dopaminergic reward areas: upstream and downstream targets of nicotine addiction. Eur J Pharmacol 2003:480:117-23. 
19 Dani JA, De Biasi M. Cellular mechanisms of nicotine addiction. Pharmacol Biochem Behav 2001;70:439-46.

20 Difranza J, Ursprung WW. A systematic review of the International Classification of Diseases criteria for the diagnosis of tobacco dependence. Addict Behav 2010;35:805-10.

21 DiFranza J, Ursprung WW, Lauzon B, et al. A systematic review of the Diagnostic and Statistical Manual diagnostic criteria for nicotine dependence. Addict Behav 2010:35:373-82.

22 US Department of Health and Human Services. Ending the tobacco epidemic: progress toward a healthier nation. Washington: US Department of Health and Human Services, Office of the Assistant Secretary for Health, 2012.

23 Maziak W, Ward KD, Afifi Soweid RA, et al. Tobacco smoking using a waterpipe: a re-emerging strain in a global epidemic. Tob Control 2004;13:327-33.

24 Cobb C, Ward KD, Maziak W, et al. Waterpipe tobacco smoking: an emerging health crisis in the United States. Am J Health Behav 2010;12:275-85.

25 *Maziak W. The global epidemic of waterpipe smoking. Addict Behav 2011;36:1-5

26 *Maziak W, Eissenberg T, Ward KD. Patterns of waterpipe use and dependence: implications for intervention development. Pharmacol Biochem Behav 2005;80:173-9.

27 Zyoud SH, Al-Jabi SW, Sweileh WM. Bibliometric analysis of scientific publications on waterpipe (narghile, shisha, hookah) tobacco smoking during the period 20032012. Tob Induc Dis 2014;12:7.

28 Knishkowy B, Amitai Y. Water-pipe (narghile) smoking: an emerging health risk behavior. Pediatrics 2005;116:e113-19.

29 *Afifi R, Khalil J, Fouad F, et al. Social norms and attitudes linked to waterpipe use in the Eastern Mediterranean Region. Soc Sci Med 2013;98:125-34.

30 Rastam S, Ward KD, Eissenberg T, et al. Estimating the beginning of the waterpipe epidemic in Syria. BMC Public Health 2004;4:32.

31 Kheirallah KA, Alzyoud S, Ward KD. Waterpipe use and cognitive susceptibility to cigarette smoking among never-cigarette smoking Jordanian youth: analysis of the 2009 Global Youth Tobacco Survey. Nicotine Tob Res Published Online First: 26 Aug 2014. pii: ntu140. PubMed PMID: 25159679.

32 *Auf RA, Radwan GN, Loffredo CA, et al. Assessment of tobacco dependence in waterpipe smokers in Egypt. Int J Tuberc Lung Dis 2012;16:132-7.

33 Harrabi I, Maaloul JM, Gaha R, et al. Comparison of cigarette and waterpipe smoking among pupils in the urban area of Sousse, Tunisia. Tunis Med 2010;88:470-3. (Reply) Con Tunis Med 2011;89:507-8.

34 Tageldin MA, Nafti S, Khan JA, et al.; BREATHE Study Group. Distribution of COPD-related symptoms in the Middle East and North Africa: results of the BREATHE study. Respir Med 2012;106 (Suppl 2):S25-32.

35 Akl EA, Gunukula SK, Aleem S, et al. The prevalence of waterpipe tobacco smoking among the general and specific populations: a systematic review. BMC Public Health 2011;11:244.

36 Morton J, Song Y, Fouad H, et al.; GATS Collaborative Group. Cross-country comparison of waterpipe use: nationally representative data from 13 low and middle-income countries from the Global Adult Tobacco Survey (GATS). Tob Control 2014:23:419-27.

37 Behera D, Uppal R, Majumdar S. Urinary levels of nicotine \& cotinine in tobacco users. Indian J Med Res 2003;118:129-33.

38 Martin R, Safaee SD, Somsamouth K, et al. Mixed methods pilot study of sharing behaviors among waterpipe smokers of rural Lao PDR: implications for infectious disease transmission. Int J Environ Res Public Health 2013;10:2120-32

39 Daniels KE, Roman NV. A descriptive study of the perceptions and behaviors of waterpipe use by university students in the Western Cape, South Africa. Tob Induc Dis 2013;11:4.

40 Dillon KA, Chase RA. Secondhand smoke exposure, awareness, and prevention among African-born women. Am J Prev Med 2010;39(6 Suppl 1):S37-43.

41 Combrink A, Irwin N, Laudin G, et al. High prevalence of hookah smoking among secondary school students in a disadvantaged community in Johannesburg. S Afr Med J 2010;100:297-9.

42 Neergaard J, Singh P, Job J, et al. Waterpipe smoking and nicotine exposure: a review of the current evidence. Nicotine Tob Res 2007;9:987-94.

43 Dugas EN, O'Loughlin EK, Low NC, et al. Sustained waterpipe use among young adults. Nicotine Tob Res 2014;16:709-16.

44 *Barreto SM, Giatti L, Oliveira-Campos M, et al. Experimentation and use of cigarette and other tobacco products among adolescents in the Brazilian state capitals (PeNSE 2012). Rev Bras Epidemiol 2014;17(Suppl 1):62-76.

45 *Kinnunen JM, Ollila H, El-Amin SE, et al. Awareness and determinants of electronic cigarette use among Finnish adolescents in 2013: a population-based study. Tob Control Published Online First: 14 May 2014. doi:10.1136/ tobaccocontrol-2013-051512

46 Schubert J, Luch A, Schulz TG. Waterpipe smoking: analysis of the aroma profile of flavored waterpipe tobaccos. Talanta 2013;115:665-74.

47 Jawad M, Abass J, Hariri $\mathrm{A}$, et al. Waterpipe smoking: prevalence and attitudes among medical students in London. Int J Tuberc Lung Dis 2013;17:137-40. Erratum in: Int J Tuberc Lung Dis 2013;17:1246.
48 Jensen PD, Cortes R, Engholm G, et al. Waterpipe use predicts progression to regular cigarette smoking among Danish youth. Subst Use Misuse 2010;45:1245-61.

49 Mach P, Zielińska-Danch W, Goniewicz MŁ, et al. Waterpipe smoking among adolescents in Silesia region of Poland. Przegl Lek 2010;67:1021-4.

50 Fromme $\mathrm{H}$, Dietrich $\mathrm{S}$, Heitmann $\mathrm{D}$, et al. Indoor air contamination during a waterpipe (narghile) smoking session. Food Chem Toxicol 2009;47:1636-41.

51 Al-Naggar RA, Saghir FS. Water pipe (shisha) smoking and associated factors among Malaysian university students. Asian Pac J Cancer Prev 2011;12:3041-7.

52 Al-Naggar RA, Bobryshev YV. Shisha smoking and associated factors among medical students in Malaysia. Asian Pac J Cancer Prev 2012;13:5627-32.

53 World Health Organization (Tobacco Free Initiative): Advisory Note. Waterpipe tobacco smoking: health effects, research needs and recommended actions by regulators. Geneva: World Health Organization, 2005.

54 *Maziak W. The waterpipe: time for action. Addiction 2008;103:1763-7.

55 AkI EA, Gaddam S, Gunukula SK, et al. The effects of waterpipe tobacco smoking on health outcomes: a systematic review. Int J Epidemiol 2010;39:834-57.

56 Maziak W, Taleb ZB, Bahelah R, et al. The global epidemiology of waterpipe smoking. Tob Control 2015;24:i3-12.

57 Sepetdjian E, Abdul Halim R, Salman R, et al. Phenolic compounds in particles of mainstream waterpipe smoke. Nicotine Tob Res 2013;15:1107-12.

58 Daher N, Saleh R, Jaroudi E, et al. Comparison of carcinogen, carbon monoxide, and ultrafine particle emissions from narghile waterpipe and cigarette smoking: sidestream smoke measurements and assessment of second-hand smoke emission factors. Atmos Environ 2010;44:8-14.

59 Al Rashidi M, Shihadeh A, Saliba NA. Volatile aldehydes in the mainstream smoke of the narghile waterpipe. Food Chem Toxicol 2008:46:3546-9.

60 Markowicz P, Löndahl J, Wierzbicka A, et al. A study on particles and some microbial markers in waterpipe tobacco smoke. Sci Total Environ 2014;499C:107-13.

61 Schubert J, Hahn J, Dettbarn G, et al. Mainstream smoke of the waterpipe: does this environmental matrix reveal as significant source of toxic compounds? Toxicol Lett 2011:205:279-84.

62 Cobb CO, Sahmarani K, Eissenberg T, et al. Acute toxicant exposure and cardiac autonomic dysfunction from smoking a single narghile waterpipe with tobacco and with a "healthy" tobacco-free alternative. Toxicol Lett 2012;215:70-5.

$63{ }^{*}$ Cobb CO, Shihadeh A, Weaver MF, et al. Waterpipe tobacco smoking and cigarette smoking: a direct comparison of toxicant exposure and subjective effects. Nicotine Tob Res 2011;13:78-87.

64 Shihadeh A, Salman R, Jaroudi E, et al. Does switching to a tobacco-free waterpipe product reduce toxicant intake? A crossover study comparing $\mathrm{CO}, \mathrm{NO}$ $\mathrm{PAH}$, volatile aldehydes, "tar" and nicotine yields. Food Chem Toxicol 2012;50:1494-8.

65 Maziak W, Rastam S, Shihadeh AL, et al. Nicotine exposure in daily waterpipe smokers and its relation to puff topography. Addict Behav 2011;36:397-9.

66 *Maziak W, Rastam S, Ibrahim I, et al. CO exposure, puff topography, and subjective effects in waterpipe tobacco smokers. Nicotine Tob Res 2009;11:806-11.

67 La Fauci G, Weiser G, Steiner IP, et al. Carbon monoxide poisoning in narghile (water pipe) tobacco smokers. CJEM 2012;14:57-9.

68 Sibai AM, Tohme RA, Almedawar MM, et al. Lifetime cumulative exposure to waterpipe smoking is associated with coronary artery disease. Atherosclerosis 2014:234:454-60.

69 *Maziak W. The waterpipe: an emerging global risk for cancer. Cancer Epidemiol 2013:37:1-4.

70 *Blachman-Braun R, Del Mazo-Rodríguez RL, López-Sámano G, et al. Hookah, is it really harmless? Respir Med 2014;108:661-7.

71 El-Zaatari Z, Chami H, Zaatari G. Health effects associated with waterpipe smoking. Tob Control 2015;24:i31-43.

72 *Hadidi KA, Mohammed FI. Nicotine content in tobacco used in hubble-bubble smoking. Saudi Med J 2004;25:912-17.

73 Kleykamp BA, Jennings JM, Sams $C$, et al. The influence of transdermal nicotine on tobacco/nicotine abstinence and the effects of a concurrently administered cigarette in women and men. Exp Clin Psychopharmacol 2008;16:99-112.

74 Blank MD, Cobb CO, Kilgalen B, et al. Acute effects of waterpipe tobacco smoking: a double-blind, placebo-control study. Drug Alcohol Depend 2011:116:102-9.

75 Jacob P 3rd, Abu Raddaha AH, Dempsey D, et al. Comparison of nicotine and carcinogen exposure with water pipe and cigarette smoking. Cancer Epidemiol Biomarkers Prev 2013;22:765-72.

76 *Jacob P 3rd, Abu Raddaha AH, Dempsey D, et al. Nicotine, carbon monoxide, and carcinogen exposure after a single use of a water pipe. Cancer Epidemiol Biomarkers Prev 2011:20:2345-53.

77 St Helen G, Benowitz NL, Dains KM, et al. Nicotine and carcinogen exposure after water pipe smoking in hookah bars. Cancer Epidemiol Biomarkers Prev 2014:23:1055-66.

78 Shafagoj YA, Mohammed Fl, Hadidi KA. Hubble-bubble (water pipe) smoking: levels of nicotine and cotinine in plasma, saliva and urine. Int J Clin Pharmacol Ther 2002;40:249-55. 
79 Eissenberg T, Shihadeh A. Waterpipe tobacco and cigarette smoking: direct comparison of toxicant exposure. Am J Prev Med 2009;37:518-23.

$80{ }^{*}$ Maziak W, Ward KD, Eissenberg T. Factors related to frequency of narghile (waterpipe) use: the first insights on tobacco dependence in narghile users. Drug Alcohol Depend 2004;76:101-6.

81 Eissenberg T. Measuring the emergence of tobacco dependence: the contribution of negative reinforcement models. Addiction 2004;99(Suppl 1):5-29.

82 *Salameh P, Waked M, Aoun Z. Waterpipe smoking: construction and validation of the Lebanon Waterpipe Dependence Scale (LWDS-11). Nicotine Tob Res 2008;10:149-58

83 *Salameh P, Salamé J, Waked M, et al. Waterpipe dependence in university students and effect of normative beliefs: a cross-sectional study. BMJ Open 2014; 4:e004378.

84 *Salameh P, Khayat G, Waked M. Lower prevalence of cigarette and waterpipe smoking, but a higher risk of waterpipe dependence in Lebanese adult women than in men. Women Health 2012;52:135-50.

85 *Salameh P, Waked M, Khoury F, et al. Chronic Bronchitis Study Group. Waterpipe smoking and dependence are associated with chronic bronchitis: a case-control study in Lebanon. East Mediterr Health J 2012;18:996-1004.

86 Salameh $\mathrm{P}$, Waked M, Khayat $\mathrm{G}$, et al. Waterpipe smoking and dependence are associated with chronic obstructive pulmonary disease: a case-control study. Open Epidemiol / 2012;5:36-44.

$87{ }^{*}$ Alzoubi KH, Khabour OF, Azab M, et al. CO exposure and puff topography are associated with Lebanese Waterpipe Dependence Scale score. Nicotine Tob Res 2013;15:1782-6.

88 Rammah M, Dandachi F, Salman R, et al. In vitro cytotoxicity and mutagenicity of mainstream waterpipe smoke and its functional consequences on alveolar type II derived cells. Toxicol Lett 2012;211:220-31.

89 *Primack BA, Khabour OF, Alzoubi KH, et al. The LWDS-10J: reliability and validity of the Lebanon Waterpipe Dependence Scale among university students in Jordan. Nicotine Tob Res 2014;16:915-22.

90 *Kassim S, Al-Bakri A, Al'Absi M, et al. Waterpipe tobacco dependence in UK male adult residents: a cross-sectional study. Nicotine Tob Res 2014;16:316-25.

91 *Fagerström K, Eissenberg T. Dependence on tobacco and nicotine products: a case for product-specific assessment. Nicotine Tob Res 2012:14:1382-90.

92 *Radwan GN, Loffredo CA, El Setouhy MA. Waterpipe smoking and the DRD2/ ANKK1 Genotype. J Egypt Public Health Assoc 2010;85:131-48.

93 Heatherton TF, Kozlowski LT, Frecker RC, et al. The Fagerström Test for nicotine dependence: a revision of the Fagerström Tolerance Questionnaire. $\mathrm{Br} J$ Addict 1991;86:1119-27.

94 Horn D, Waingrow S. Behavior and attitudes questionnaire. Bethesda, MD, USA: National Clearinghouse for Smoking and Health, 1996.

95 Chase HW, Mackillop J, Hogarth L. Isolating behavioural economic indices of demand in relation to nicotine dependence. Psychopharmacology (Berl) 2013:226:371-80.

96 Griffiths RR, Rush CR, Puhala KA. Validation of the multiple-choice procedure for investigating drug reinforcement in humans. Exp Clin Psychopharmacol 1996:4:97-106

97 Rastam S, Eissenberg T, Ibrahim I, et al. Comparative analysis of waterpipe and cigarette suppression of abstinence and craving symptoms. Addict Behav 2011:36:555-9.

98 *Jackson D, Aveyard P. Waterpipe smoking in students: prevalence, risk factors, symptoms of addiction, and smoke intake evidence from one British university. BMC Public Health 2008:8:174.

$99{ }^{*}$ Hammal F, Mock J, Ward KD, et al. A pleasure among friends: how narghile (waterpipe) smoking differs from cigarette smoking in Syria. Tob Control 2008;17:e3.

100 *Jawad M, Jawad S, Mehdi A, et al. A qualitative analysis among regular waterpipe tobacco smokers in London universities. Int I Tuberc Lung Dis 2013;17:1364-9.

101 *Ward KD, Hammal F, VanderWeg MW, et al. Are waterpipe users interested in quitting? Nicotine Tob Res 2005;7:149-56.

102 *Asfar T, Al Ali R, Rastam S, et al. Behavioral cessation treatment of waterpipe smoking: the first pilot randomized controlled trial. Addict Behav 2014:39:1066-74.

103 Shishani K, Howell D, McPherson S, et al. Young adult waterpipe smokers: smoking behaviors and associated subjective and physiological effects. Addict Behav 2014:39:1113-19.

104 Cobb CO, Blank MD, Morlett A, et al. Comparison of puff topography, toxicant exposure, and subjective effects in low- and high-frequency waterpipe users: a double-blind, placebo-control study. Nicotine Tob Res Published Online First: 25 Sep 2014 doi:10.1093/ntr/ntu196
105 Perkins KA, Stiller RL, Jennings JR. Acute tolerance to the cardiovascular effects of nicotine. Drug Alcohol Depend 1991;29:77-85.

106 *McKelvey KL, Wilcox ML, Madhivanan P, et al. Time trends of cigarette and waterpipe smoking among a cohort of school children in Irbid, Jordan, 2008-11. Eur J Public Health 2013;23:862-7.

107 Sharma E, Clark PI, Sharp KE. Understanding psychosocial aspects of waterpipe smoking among college students. Am J Health Behav 2014;38:440-7.

108 Alzyoud S, Kheirallah KA, Weglicki LS, et al. Tobacco smoking status and perception of health among a sample of Jordanian students. Int I Environ Res Public Health 2014;11:7022-35

109 Arfken CL, Abu-Ras W, Ahmed S. Pilot Study of Waterpipe Tobacco Smoking among US Muslim College Students. J Relig Health Published Online First: 6 May 2014. doi:10.1007/s10943-014-9871-x

110 Jawad M, Bakir AM, Ali M, et al. Key health themes and reporting of numerical cigarette-waterpipe equivalence in online news articles reporting on waterpipe tobacco smoking: a content analysis. Tob Control 2015;24:43-7.

111 Akl EA, Jawad M, Lam WY, et al. Motives, beliefs and attitudes towards waterpipe tobacco smoking: a systematic review. Harm Reduct J 2013;10:12.

112 *Heinz AJ, Giedgowd GE, Crane NA, et al. A comprehensive examination of hookah smoking in college students: use patterns and contexts, social norms and attitudes, harm perception, psychological correlates and co-occurring substance use. Addict Behav 2013:38:2751-60.

113 Martinasek MP, Gibson-Young L, Forrest J. Hookah smoking and harm perception among asthmatic adolescents: findings from the Florida youth tobacco survey. J Sch Health 2014;84:334-1.

114 Vansickel AR, Shihadeh A, Eissenberg T. Waterpipe tobacco products: nicotine labelling versus nicotine delivery. Tob Control 2012;21:377-9.

115 * Maynard OM, Gage SH, Munafò MR. Are waterpipe users tobacco-dependent? Addiction 2013;108:1886-7.

116 Fong GT, Cummings KM, Borland R, et al. The conceptual framework of the international tobacco control (ITC) policy evaluation project. Tob Control 2006 ; 15(Suppl III):iii3-11.

117 Fong GT, Cummings KM, Shopland DR. Building the evidence base for effective tobacco control policies: the International Tobacco Control Policy Evaluation Project (the ITC Project). Tob Control 2006;15(Suppl III):iii1-2.

118 Ashurst JV, Urquhart M, Cook MD. Carbon monoxide poisoning secondary to hookah smoking. J Am Osteopath Assoc 2012;112:686-8.

119 Lim BL, Lim GH, Seow E. Case of carbon monoxide poisoning after smoking shisha. Int J Emerg Med 2009;2:121-2.

120 Uyanık B, Arslan ED, Akay H, et al. Narghile (hookah) smoking and carboxyhemoglobin levels. J Emerg Med 2011;40:679.

121 Ozkan S, Ozturk T, Ozmen Y, et al. Syncope associated with carbon monoxide poisoning due to narghile smoking. Case Rep Emerg Med 2013;2013: 796857.

122 Lopez AD, Collishaw NE, Piha T. A descriptive model of the cigarette epidemic in developed countries. Tob Control 1994;3:242-7.

123 Jha P, Chaloupka F, eds. Tobacco control in developing countries. Oxford, UK: Oxford University press, 2000.

124 Wakefield M, Chaloupka F. Effectiveness of comprehensive tobacco control programmes in reducing teenage smoking in the USA. Tob Control 2000;9: $177-86$.

125 Stephens T, Pederson LL, Koval JJ, et al. Comprehensive tobacco control policies and the smoking behaviour of Canadian adults. Tob Control 2001:10:317-22.

126 Levy DT, Chaloupka F, Gitchell J. The effects of tobacco control policies on smoking rates: a tobacco control scorecard. J Public Health Manag Pract 2004;10:338-53.

127 Taylor AL, Bettcher DW. WHO Framework Convention on Tobacco Contro: a global "good" for public health. Bull World Health Organ 2000;78:920-9.

128 Shibuya K, Ciecierski C, Guindon E, et al. WHO Framework Convention on Tobacco Control: development of an evidence based global public health treaty. BMJ 2003:327:154-7.

129 World Health Organization. Framework Convention on Tobacco Control. 2003. Retrieved June, 7, 2011. http://www.who.int/tobacco/framework/download/en/

130 Nakkash R, Khalil J. Health warning labeling practices on narghile (shisha, hookah) waterpipe tobacco products and related accessories. Tobacco Control 2010;19:235-9.

131 *Maziak W, Ward KD, Eissenberg T. Interventions for waterpipe smoking cessation. Cochrane Database Syst Rev 2007;(4):CD005549. 